\title{
Open problems in traceability: from raw materials to finished food products
}

\author{
Lorenzo Comba, ${ }^{1}$ Fabrizio Dabbene, ${ }^{2}$ Paolo Gay, ${ }^{1,2}$ Cristina Tortia ${ }^{1}$ \\ 1 DI.S.A.F.A, Università di Torino, Grugliasco (TO), Italy; ${ }^{2}$ CNR-IEIIT, Torino, Italy
}

\begin{abstract}
Even though the main EU regulations concerning food traceability have already entered to force since many years, we still remark very wide and impacting product recalls, which often involve simultaneously large territories and many countries. This is a clear sign that current traceability procedures and systems, when implemented with the only aim of respecting mandatory policies, are not effective, and that there are some aspects that are at present underestimated, and therefore should be attentively reconsidered. In particular, the sole adoption of the so-called "one step back-one step forward traceability" to comply the EC Regulation $178 / 2002$, where every actor in the chain handles merely the data coming from his supplier and those sent to his client, is in fact not sufficient to control and to limit the impact of a recall action after a risk notification. Recent studies on lots dispersion and routing demonstrate that each stakeholder has to plan his activities (production, transformation or distribution) according to specific criteria that allow pre-emptively estimating and limiting the range action of a possible recall. Moreover, these new and very recently proposed techniques still present some limits; first of all the problem of traceability of bulk products (e.g. liquids, powders, grains, crystals) during production phases that involve mixing operations of several lots of different/same materials. In fact, current traceability practices are in most cases unable to deal efficiently with this kind of products, and, in order to compensate the lack of knowledge about lot composition, typically resort to the adoption of very large lots, based for instance on a considered production period. Aim of this paper is to present recent advances in the design of supply chain traceability systems, discussing problems that are still open and are nowadays subject of research.
\end{abstract}

Correspondence: Paolo Gay, DI.S.A.F.A - Università di Torino, 44 via Leonardo da Vinci, 10095 Grugliasco (TO) - Italy.

E-mail: paolo.gay@unito.it

Key words: traceability, supply chain, bulk products.

Acknowledgements: this work was partially supported by the grants of the projects Namatech-Converging Technologies (CIPE2007), Regione Piemonte, Italy and PRIN 2009 (prot. 2009FXN7HW_002), MIUR, Italy.

(C) Copyright L. Comba et al., 2013

Licensee PAGEPress, Italy

Journal of Agricultural Engineering 2013; XLIV(s2):e30

doi:10.4081/jae.2013.s2.e30

This article is distributed under the terms of the Creative Commons Attribution Noncommercial License (by-nc 3.0) which permits any noncommercial use, distribution, and reproduction in any medium, provided the original author(s) and source are credited.

\section{Introduction}

A traceability system (TS) has to the assignment to provide strategic information in the unfortunate case when a lot of product has to be recalled. Product recalls are an increasing concern for food companies and government agencies (e.g. FDA for US and RASFF for EU). Traceability can be voluntary, when disposed by the food manufacturer itself, or forced (Kramer et al., 2005).

The main causes of product recalls are incorrect labelling and packaging, failures in good manufacturing practice, and, of course, the identification of conditions that can compromise the safety of the food and consumer's health (chemical contamination, microbial agents, foreign material, undercooking of product etc.). Another frequent cause is the (undeclared or accidental) contamination of raw and semi-processed materials with allergens (especially eggs, peanuts, dairy and wheat). The occurrence of food and feed recalls is increasing (Potter et al., 2012) and in the EU, in 2011, exceeded 3700 notification cases. This fact can also be imputed to food safety standards and new government regulations, to the development of new detection technologies and the increasing importation from low-cost countries, where food safety standards are frequently less severe.

The management of a recall procedure involves many activities, ranging from the risk assessment, the identification of the interested products, the notification of the measure to the actors of the supply chain (suppliers, distributors, buyers etc.), and, finally, the recall action. Wynn et al. (2011) identified common data requirements for traceability and data exchange, and analysed opportunities for the automation of the notification process in the case of a recall.

There are many consequences in a recall action. One of the first, is the potential drop in consumer confidence (Kumar and Budin, 2006; Skees et al., 2001). Indeed, a negative image of the brand can remain in the subconscious of potential consumers for long periods. The company has then to incur costs related to the logistics of the recall and the destruction of all the products that are, in some way, connected with the incriminated batch (Jacobs, 1996).

Since this could be absolutely critical for a company, it is important to prepare action plans to be ready to such undesired event. Some studies have been carried on for modelling and forecasting the effects of recall actions (e.g., see Kumar and Budin, 2006, Randrup et al., 2008 and Fritz and Schiefer, 2009). What resulted is that most companies do not have reliable methods to manage a recall strategy on the basis on estimation the real amount of product that has to be discarded in the case of a recall. The recall of a product typically follows two steps that should be be performed in very short time: the backward identification of potential deficient lots and then the forward identification of potentially affected products that have to be withdrawn (Fritz and Schiefer, 2009). Considering the main task of TS, the performances of a TS can therefore be associated to its ability to react to a crisis, holding down the amount and the costs of the product to be recalled.

Following the entering to force of EC Regulation 178/2002 and subsequent normative, traceability has evolved in different directions, engaging many aspects among which the definition of optimal lot sizes 
and mixing routing rules, the tracking of products in distribution networks and the embedding of product quality information for supply chain managements purposes.

This paper presents a brief overview of the state of the art of the research on traceability and the open problems nowadays subject of research. To enter in a deeper detail, authors have chosen two two specific aspects: the definition and the evaluation of the performances of a traceability system (TS) connected to the minimization of the impact of a possible product recall, and the management of traceability information related to bulk products. These research lines have been selected considering their impact on the supply chains, on the market, and on the consumer, and the very recent results published in literature. These arguments are very up-to-date and rich of ongoing applications in different food supply chains. The paper is organized in two main sections dedicated to these topics and a Conclusions section where future trends and perspectives are discussed.

\section{Performances evaluation of traceability systems}

The definition and the evaluation of the performance of a traceability system is a fundamental step to compare different approaches and technologies and to judge new possible traceability oriented management policies. Many different criteria have been proposed which are mainly based on these factors:

- the cost of a possible product recall;

- the degree of dispersion of raw materials and intermediates;

- the speed of the TS in supplying information and to act to a crisis.

Most part of the performance definitions presented in literature allows the determination of quantitative indexes that can be used by optimization procedures. In this case, performances can be enhanced acting on logistics, lot definition and sizing, and, more in general, production management rules and plans. In other cases, e.g. the reduction of the response time of the TS, an enhancement of the performances can be obtained upgrading and expanding the information management tools and the level of automation in the supply chain, i.e. investing in the TS.

To formalize some elements in performance measurement criteria, some nomenclature concerning lots, their management, and size has to be introduced. Moe (1998), following the terminology firstly introduced by Kim et al. (1995), introduced the traceable resource unit (TRU) as "unique unit, meaning that no other unit can have exactly the same, or comparable, characteristics from the point of view of traceability". This concept has been then described in ISO Standard 22005/2007 (ISO, 2007). Here the lot is defined as "set of units of a product which have been produced and/or processed or packaged under similar circumstances".

A further elaboration of this concept was proposed by Bollen et al. (2007) introducing the identifiable unit (IU), which represents the unit of product that have to be uniquely identifiable within each system. From the size of IUs it descends the granularity of the traceability system, which can be expressed as the size of the smallest TU managed by the TS (Karlsen et al., 2012). Indeed, granularity level is determined by size and number of batches. A finer granularity allows adding even more detailed information about the product, and acting at a more detailed and range-limited level in the case of a possible recall. The size of batches is important for companies in reducing risk and the wideness of repercussions. The optimal granularity level is very difficult to determine, since it depends on product type and customer. Indeed, it should be remarked that the simple implementation of a finer granu- larity has no value by itself, unless it provides more precise traceability. Moreover, the way a product is processed has to be taken into account. In particular, whether the product is processed in completely separated sessions (i.e. separated batches), or if some mixing can occur between products of two succeeding batches. In the case of mixing, which is typical for bulk commodities (liquids, powders, crystals, grains etc.), is still an open problem and is discussed in Section 4.

A first approach for performance measurement is to consider a recall cost $(R C)$ connected to the material that has to be recalled in the case of crisis. Such cost depends on different factors such as i) the size of the batches that have been individually tracked and managed by the traceability system, ii) the way the batches of the different materials have been processed and mixed to obtain the final product, and iii) the level of segregation adopted by the firm to manage and maintain separated different batches of product. Direct costs associated to a recall action include the costs for the notification of the recall, the logistics to retrieve the product and lost sales. Resende-Filho and Buhr (2010) consider all these cost components, as a whole, as directly proportional to the amount of product to be recalled, that is $R C=\alpha P_{r} Q_{R}$ where $Q_{R}$ represents the quantity of product to be recalled, $P_{r}$ the retail value of the product, and $\alpha$ is a coefficient accounting for notification and logistics. Analogously, Fritz and Schiefer (2009) express the overall recall cost of a TS as the sum of the cost of the system $C(t t)$, the costs induced by the possible reductions in efficiency $C(e)$ and in quality $C(q)$ caused by the adoption of the tracking and tracing system, i.e. $C$ (overall $)=$ $R C+C(t t)+C(e)+C(q)$

In other cases the performances were associated to the degree of dispersion of the lot of products. This indirect measure of $R C$ was firstly proposed in Dupuy et al. (2005) as downward and upward dispersion indices and, more in general, as batch dispersion cost (BDC). The downward dispersion of a lot represents the number of batches of finished product that contains part of the lot, while the upward dispersion of a finished lot of product is constituted by the number of raw material lots used to produce the lot. The sum of downward and upward dispersion indices of all raw materials gives the measure of the total batch dispersion of a system. It follows that when the performance of a traceability system is associated to batch dispersion, it is measured by the number of active paths (links) between raw materials and finished products. Rong and Grunow (2010) introduced the chain dispersion measure, which can be specifically applied to the distribution phase, defined as

$$
D_{b}=\frac{n(n-1)}{2}
$$

where $\eta$ is the number of retailers served by the lot $b$. As for the batch dispersion cost, the chain dispersion measure depends on the number of links, but it increases quadratically for $n>1$. However, it should be remarked that the typical interest of a company is to know the worstpossible amount of product that could be necessary to recall. For this reason, Dabbene and Gay (2011) associated to the performance measure of a TS the worst-case recall cost (WCRC) index, defined as the largest amount of product that has to be recalled when a batch of raw material results unsafe. Analogously, the average recall cost (ARC) index was introduced to represents the average mass of product to be recalled when one of the entering material is found inappropriate. The formalism introduced in Dupuy et al. (2005) and then in Dabbene and Gay (2011) stems from the consideration that, from a traceability viewpoint, the production process can be modelled as an interconnected graph, where nodes represents the different lots of raw/intermediate materials, and the arrows represent the mixing operations that lead to the final lots of product.

Degradation in the TS performance occurs whenever systematic 
information loss takes place, as for instance when information about the composition or process conditions is not properly linked to the product and systematically recorded. This corresponds to a loss in precision and of the granularity level of the TS. Karlsen et al. (2010) defined the point where this loss occurs as critical traceability point (CTP). Following a similar to HACCP approach, the identification and mapping of CTPs is performed by qualitative methods (direct observation, structured interviews and document analysis), and leads to the definition of a critical traceability point analysis plan (Karlsen and Olsen, 2011). Some application of CTP mapping and validation can be found in Donnelly et al. (2009); see also Karlsen et al. (2011) and references therein. Finally, an important aspect of the TS and its performance evaluation, as also reported in ISO Standard 22005/2007, is the definition of monitoring procedures and schemes to evaluate the effectiveness of the system. For some particular types of foodstuff, specific physicochemical and microbiological analytical techniques have been developed for determining the origin with a good level of precision (Peres et al., 2007). Validation should be performed periodically by verifying the fulfilment of the desired level of the TS performances, for instance by simulating product recalls. A study on simulated recall in the case of Nordic fish products is reported in Randrup et al. (2008).

\section{Traceability of bulk products}

In many food plants, raw or semiprocessed products are handled as liquids (as e.g. milk, vegetal oils, etc.), powders (e.g. cocoa, powdered milk, flour etc.), crystals (e.g. salt, sugar) or grains. These products, for which is in almost all cases impossible to associate a label, a marker or any other identifier, are usually stored in tanks or huge silos, which are very rarely completely emptied. It follows that many lots are contemporarily kept in the same container. During the production phases, ingredients are mixed to obtain the desired final or semiprocessed product. There are indeed situations in which different lots cannot be mixed. This is the case, for instance, of products subject to religious specifications (e.g. Kosher or Halal certifications), or military supply contracts, or the case of products subject to very particular safety issues and constraints. In these cases, the only possible way to process raw materials and food is to guarantee complete and absolute segregation of lots using separated containers and/or accurately washing (or even sterilizing) the processing plants before their use with these lots. For these cases, the problem of traceability is even simpler, because raw materials and products are managed at whole lot level. However, in the great majority of cases, lots of bulk products are somehow mixed and/or they make use of the same facilities and plants, and are therefore naturally subject to thresholds. As an example, even the differentiation between non-GM from GM grains, which has important economical and ethical implications, is formally established and verified using a threshold where, in detail, EC Regulation No 1829/2003 (European Commission, 2003) for genetic modified (GM) and non-GM grains labelling guarantee that any food containing material that contains more than $0.9 \%$ of GM would be labelled as "contains GM". The problem of the traceability of fluid products has been first addressed as fuzzy traceability by Skoglund and Dejmek (2007) where dynamic simulation of continuous processing is used to model the changeover of lots of liquid product, in a pipe. In absence of a cleaning operation between the processing of two subsequent lots, portions of product, defined as virtual batches, deriving from the partial mixing of two lots are generated. This methodology is especially addressed for continuous processes on fluid products as sterilization and pasteurization where lots of products are supplied in sequence to the plant. In some case the flow of a product can be monitored mixing to the product specific identifiers that can be detected by the TS. This is the case, for example, of particular pillsize food-grade tracers inserted into grains (Liang et al., 2012; Lee et al., 2010) carrying identity information by means of printed bar codes or data matrix. For the cases in which this solution cannot be pursued, Comba et al. (2013) recently proposed a methodology based on compartmental models (Godfrey, 1983), which is applicable to any kind of bulk product including powders, grains, and fluids, where the definition of lot given in the ISO Standard 22005/2007 is rigorously formalized introducing a criterion, named composition-distance, to formally establish the homogeneity of a lot from the point of view of its composition in terms of raw materials that need to be tracked. The composition distance measures the difference of two products in terms of percentage content of supply-lots (raw materials), thus leading to formal definition of homogeneity: two portions of product can be considered as homogenous (and hence part of a single lot) if their composition-distance is less than a given quantization level. This approach is in accordance with the current regulation for the management and traceability of genetically modified (GM) products (European Commission 2003a,b), which states that a product can be labelled as GM-free if its percentage GM content is less than $0.9 \%$. The management of homogenous lots of products (referred to as cohorts) and of their flow inside the production line is then governed by means compartmental models. This methodology allows to track the composition, in terms of lots of raw material, of any portion of product processed in the plant, and has been previously successfully used in (Comba et al., 2011) to determine precise thermal conditions of fluid product processed in mixed continuous-discontinuous condition (i.e. plants with valves and pumps that can introduce discontinuities in the product flow). Another interesting approach has been proposed by Bollen et al. (2007) and by Riden and Bollen (2007). They considered the transport of discrete items (apples) that, once fluidized considering average flows, can be connected to flow of any bulk material. In their setting, apples, supplied to the packhouse in bulk bins, are moved in a water dump bulk flow up to the grader operators that handle single fruits and directs them into packaging lines of the sorting machine. At the end of these lines the fruits are placed into colour/size homogeneous packs. During their flow in the water dump and then in the packaging lines, a level of mixing among lots of apples occurs. In their first paper, Bollen et al. (2007) developed and validated a set of statistical models, using the measured arrival sequence of 100 blue marker balls, that indicates the composition, in a probabilistic setting, of a outgoing lot. The proposed models are indeed able to assign a probability of bin origin to any individual fruit in the final packs.

\section{Conclusions}

Traceability is becoming more and more a strategic tool that, in addition to its first task of guaranteeing consumers' safety, can help companies in the management of the production. The definition and the optimization of performance measures of the TSs lead to the a-priori determination and reduction of the risk at which a company is exposed in the case of possible product recall. The availability of this information will help companies in designing plant facilities and planning the production. What we expect in the next future is the development at a commercial level of these new tools as an integral part of ERP and traceability software. This is a living matter and therefore standards have even now to be accepted. The availability of reliable methods to estimate and trace the composition of lots, especially for bulk products, without resorting to the currently often-adopted process of oversizing the lots, allows the proper identification and definition of batches of homogeneous product. In particular, the availability of precise information about the composition, in terms of lots of raw or intermediate 
ingredients, introduces the possibility to correlate product data with raw materials and then to optimise the recipes for each final product type. Also in this case we expect the development of new traceability software able to manage this kind of information and the tuning of sensors and identification devices able to guarantee a real-time validation of the simulated results.

\section{References}

Bollen, A. F., Riden, C. P., \& Cox, N. R. (2007). Agricultural supply system traceability, Part I: Role of packing procedures and effects of fruit mixing. Biosystems Engineering, 98(4), 391-400. doi:10.1016/j.biosystemseng.2007.07.011

Comba, L., Belforte, G., \& Gay, P. (2011). Modelling techniques for the control of thermal exchanges in mixed continuous-discontinuous flow food plants. Journal of Food Engineering, 106(3), 177-187. doi:10.1016/j.jfoodeng.2011.04.015

Comba, L., Belforte, G., Dabbene, F., \& Gay, P. (2013). Methods for traceability in food production processes involving bulk products, Biosystems Engineering, in press.

Dabbene, F., \& Gay, P. (2011). Food traceability systems: Performance evaluation and optimization. Computers and Electronics in Agriculture, 75(1), 139-146. doi:10.1016/j.compag.2010.10.009

Donnelly, K. A.-M., Karlsen, K. M., \& Olsen, P. (2009). The importance of transformations for traceability - A case study of lamb and lamb products. Meat Science, 83(1), 68-73. doi:10.1016/j.meatsci.2009.04.006

Dupuy, C., Botta-Genoulaz, V., \& Guinet, A. (2005). Batch dispersion model to optimise traceability in food industry. Journal of Food Engineering, 70(3), 333-339. doi:10.1016/j.jfoodeng.2004.05.074

European Commission (2002). Regulation (EC) No 178/2002 of the European Parliament and of the council of 28 January 2002 laying down the general principles and requirements of food law, establish the European Food Safety Authority and laying down procedures in matters of food safety. Official Journal of the European Union, L31, 1-24 (28.01.02).

European Commission. (2003a). Regulation (EC) No 1829/2003 of the European Parliament and of the Council of 22 September 2003 concerning the traceability and labeling of genetically modified organisms and the traceability of food and feed products produced from genetically modified organisms and amending directive 2001/18/EC. Official Journal of the European Union L268, 1-23.

European Commission (2003b). Regulation (EC) No 1830/2003 of the European Parliament and of the Council of 22 September 2003 concerning the traceability and labeling of genetically modified organisms and the traceability of food and feed products produced from genetically modified organisms and amending directive 2001/18/EC. Official Journal of the European Union, L268, 18/10/2003, 24-28

Fritz, M., \& Schiefer, G. (2009). Tracking, tracing, and business process interests in food commodities: A multi-level decision complexity. International Journal of Production Economics, 117 (2), 317-329, doi:10.1016/j.ijpe.2008.10.015

Godfrey, K. (1983). Compartmental Models and Their Applications. Academic Press, London and New York.

ISO (2007). ISO Standard 22005/2007. Traceability in the feed and food chain: general principles and basic requirements for system design and implementation.

Jacobs R.M. (1996): Product recall - a vendor/vendee nightmare. Microelectronics reliability, 36 (1), 101-103, doi: 10.1016/00262714(95)00001-I

Karlsen, K.M., Donnelly, K.A.-M., \& Olsen, P. (2010). Implementing traceability: practical challenges at a mineral water bottling plant. British
Food Journal, 112 (2), 187-197

Karlsen, K.M., \& Olsen, P. (2011). Validity of method for analysing critical traceability points. Food Control, 22 (8), 1209-1215, doi:10.1016/.foodcont.2011.01.020

Karlsen, K. M., Donnelly, K. A.-M., \& Olsen, P. (2011). Granularity and its importance for traceability in a farmed salmon supply chain. Journal of Food Engineering, 102(1), 1-8. doi:10.1016/j.jfoodeng.2010.06.022

Karlsen, K.M., Dreyer, B., Olsen, P., \& Elvevoll, E. (2012). Granularity and its role in implementation of seafood traceability. Journal of Food Engineering, 112 (1-2), 78-85, doi:10.1016/j.jfoodeng.2012.03.025

Kim, H., Fox, M., \& Gruninger, M. (1995). An ontology of quality for enterprise modelling. Proceedings of the Fourth Workshop on Enabling Technologies: Infrastructure for Collaborative Enterprises , 105-116.

Kramer, M., Coto, D., \& Weidner, J. (2005). The science of recalls. Meat Science, 71 (1), 158-163, doi:10.1016/j.meatsci.2005.04.001

Kumar, S., \& Budin, E. (2006). Prevention and management of product recalls in the processed food industry: a case study based on an exporter's perspective. Technovation, 26 (5), 739-750, doi:10.1016/ j.technovation.2005.05.006

Lee, K.-M., Armstrong, P. R., Thomasson, J. A., Sui, R., Casada, M., \& Herrman, T. J. (2010). Development and Characterization of FoodGrade Tracers for the Global Grain Tracing and Recall System. Journal of Agricultural and Food Chemistry, 58(20), 10945-10957. doi:10.1021/jf101370k

Liang, K., Thomasson, J. A., Lee, K.-M., Shen, M., Ge, Y., \& Herrman, T. J. (2012). Printing data matrix code on food-grade tracers for grain traceability. Biosystems Engineering, 113(4), 395-401. doi:10.1016/j.biosystemseng2012.09.012

Peres, B., Barlet, N., Loiseau, G. and Montet, D. (2007). Review of the current methods of analytical traceability allowing determination of the origin of foodstuffs. Food Control, 18(3), 228-235, doi:10.1016/j.foodcont.2005.09.018

Potter, A., Murray, J., Lawson, B., \& Graham, S. (2012). Trends in product recalls within the agri-food industry: Empirical evidence from the USA, UK and the Republic of Ireland. Trends in Food Science \& Technology, 28, 77-86, doi: 10.1016/j.tifs.2012.06.017

Moe, T. (1998). Perspectives on traceability in food manufacture. Trends in Food Science \& Technology, 9(5), 211-214. doi:10.1016/S09242244(98)00037-5

Randrup, M., Storøy, J., Lievonen, S., Margeirsson, S., Árnason, S. V., Ólavsstovu, D. í, ... Frederiksen, M. T. (2008). Simulated recalls of fish products in five Nordic countries. Food Control, 19(11), 1064-1069. doi:10.1016/j.foodcont.2007.11.005

Riden, C. P., \& Bollen, A. F. (2007). Agricultural supply system traceability, Part II: Implications of packhouse processing transformations. Biosystems Engineering, 98(4), 401-410. doi:10.1016/j.biosystemseng. 2007.07.004

Resende-Filho, M. \& Buhr, B.L. (2010). Economics of Traceability for Mitigation of Food Recall Costs. Available at: http $/ /$ ssrn.com/abstract= 995335, doi:10.2139/ssrn.995335

Rong, A., \& Grunow, M. (2010). A methodology for controlling dispersion in food production and distribution. OR Spectrum, 32(4), 957-978. doi:10.1007/s00291-010-0210-7

Skees, J., Botts, A., \& Zeuli, K. (2001). The potential for recall insurance to improve food safety. International Food and Agribusiness Management Review, 4, 99-111, doi: 10.1016/S1096-7508(01)00072-6

Skoglund, T., \& Dejmek, P. (2007). Fuzzy Traceability: A Process Simulation Derived Extension of the Traceability Concept in Continuous Food Processing. Food and Bioproducts Processing, 85(4), 354-359. doi:10.1205/fbp07044

Wynn, M., Ouyang, C., ter Hofstede, A., \& Fidge, C. (2011). Data and process requirements for product recall coordination. Computers in Industry, 62, 776-786, doi:10.1016/j.compind.2011.05.003 